\title{
The new WMO RA VI Regional Climate Centre Node on Climate Monitoring
}

\author{
J. Rapp, H. Nitsche, and P. Bissolli \\ Deutscher Wetterdienst, Regional Climate Centre Node on Climate Monitoring (WMO RA VI), \\ Frankfurter Str. 135, 63067 Offenbach am Main, Germany
}

Received: 29 December 2010 - Revised: 10 June 2011 - Accepted: 1 August 2011 - Published: 9 August 2011

\begin{abstract}
Regional Climate Centres are institutions with the capacity and mandate by WMO to develop high quality regional-scale products using global products, national input and incorporating regional information. Recently a pilot network of three Regional Climate Centre consortia was established for the WMO region RA VI (Europe and Middle East). Germany (Deutscher Wetterdienst) has taken the responsibility of the Regional Climate Centre Node on Climate Monitoring. The main basic functions of this centre are the publication of annual and monthly climate diagnostic bulletins, monthly monitoring maps, monitoring of significant events, implementation of a climate watch system, capacity building and offering reference climatologies and trend maps.
\end{abstract}

\section{Background}

Climate relevant processes have strong inter-scale linkages going beyond borders of individual countries. Therefore, and also to meet the needs of its members, WMO has defined a worldwide three-level infrastructure: Global Producing Centres for Long-range Forecasts (GPCs), Regional Climate Centres (RCCs; WMO, 2009) and National Meteorological or Hydrometeorological Services (NMHSs).

In the light of the enormous challenges climate variability and climate change pose to societies, there is an urgent need to enable WMO Members to provide the best possible climate services in support of climate risk management and adaptation. As global-scale information provided by GPCs (coarse in terms of resolution and reflected features) is typically not sufficient for national-scale services, the concept of WMO Regional Climate Centres was developed to bridge the gap between information at the global and national scales. Moreover, up-to-date climate services require, among others, appropriate computer power, modelling capacities and special expertise, to which not all WMO Members currently have adequate access.

WMO Global Producing Centres (GPCs) for Long Range Forecasts (global seasonal forecasts) are an integral part of the Global Data-Processing and Forecasting System (GDPFS). GPCs adhere to certain well-defined standards -

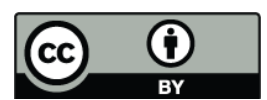

Correspondence to: J. Rapp

(joerg.rapp@dwd.de) aiding consistency and usability of output: a fixed forecast production cycle, a standard set of forecast products and WMO-defined verification standards (for retrospective forecasts). A comprehensive set of standard verification measures, with which to communicate the skill of forecasts, has also been defined.

Officially designated GPCs of Long Range Forecasts based in Europe are: the European Centre for MediumRange Weather Forecasts (ECMWF), Toulouse (MétéoFrance, France), Exeter (Met Office, UK), and Moscow (Roshydromet, Russia). WMO has also designated a Lead Centre for Long Range Forecast Multi-Model Ensemble (LC-LRFMME) and for Standard Verification System of Long Range Forecasts (LC-SVSLRF).

Regional Climate Centres (RCC) are Centres of Excellence that assist World Meteorological Organization (WMO) Members in a given region to deliver better climate services and products including regional long-range forecasts, and to strengthen their capacity to meet national climate information needs. The concept of Regional Climate Centres (RCC) offers excellent opportunities for networking by pooling certain capacities of the National Meteorological and Hydrological Services (NMHSs) and other institutes in a region by an efficient systems approach. Accordingly, each member in a region gets sustained operational access to the most updated climate services. The primary users of an RCC are the NMHSs and other RCCs in the region and in neighbouring areas. NMHSs typically use RCC products to extend or improve their service suite vis-à-vis their end user community. 


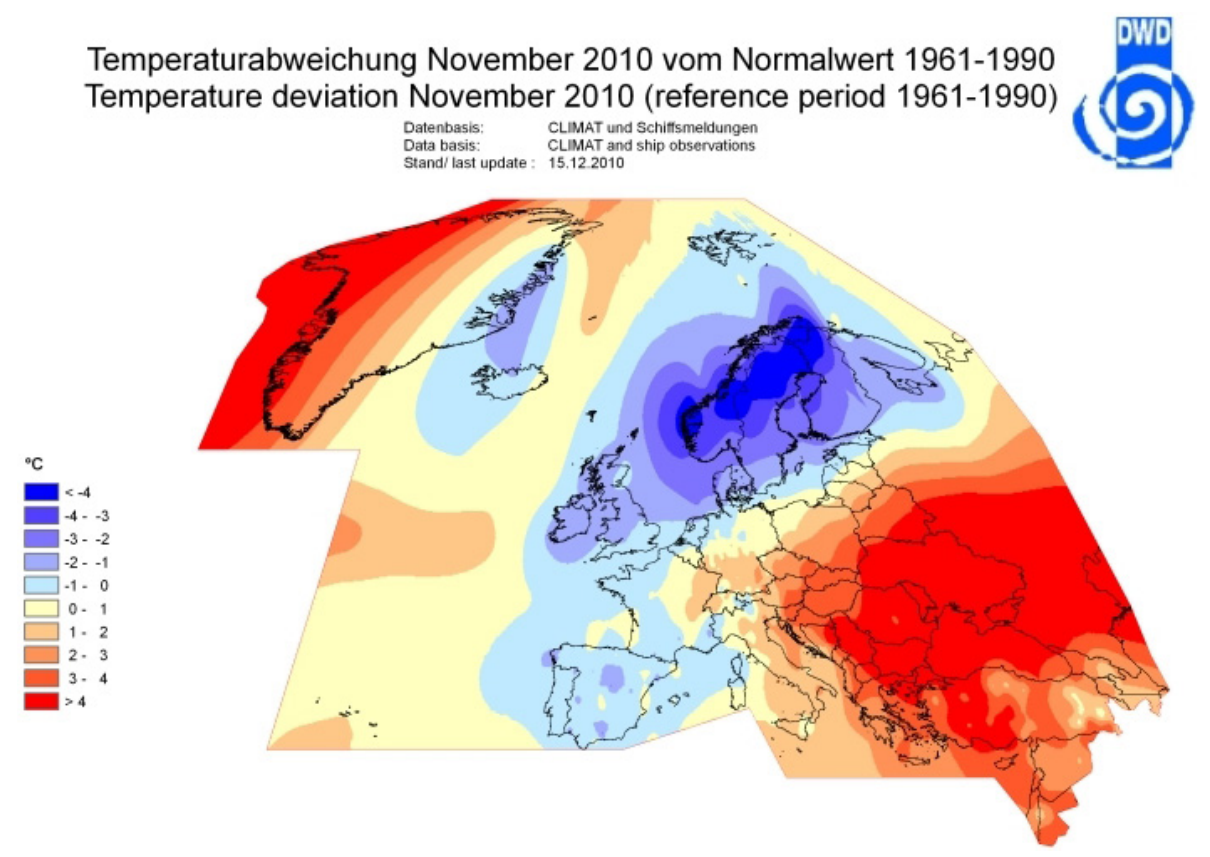

Figure 1. Example map of monthly temperature anomaly in November 2010 (Source: Deutscher Wetterdienst).

\section{Organization}

Recently a pilot network of three RCC consortia was established for the WMO region Regional Association (RA) VI (Europe and Middle East) which comprises Europe, Greenland, parts of the North Atlantic and the Middle East (http: //www.rccra6.org):

- RCC node on climate data (http://eca.knmi.nl),

- RCC node on climate monitoring (www.dwd.de/rcc-cm),

- RCC node on long-range forecasting (http://neacc.meteoinfo.ru/).

Germany (Deutscher Wetterdienst, DWD) has taken the responsibility of the RCC node on climate monitoring (RCC$\mathrm{CM}$ ). The consortium of this node consists of the following NHMSs

- Armstatehydromet/Armenia,

- Deutscher Wetterdienst (Germany) (host),

- Météo-France/France,

- KNMI/The Netherlands,

- RHMS/Serbia, and

- TSMS/Turkey.
RCC-CM supports the South-eastern Europe Climate Outlook Forum (SEECOF). It is the very first regional climate outlook forum in Europe, started in 2008 at Zagreb, Croatia. Regional Climate Outlook Forums (RCOFs), active in several parts of the world, routinely provide real-time regional climate outlook products.

\section{Basic functions and products}

RCCs provide online access to their products and services to National Meteorological and Hydrological Services (NMHSs) and to other regional users (if respective NMHSs agree). Vice versa, RCCs receive data, products, know-how and feedback from the NMHSs as a main source for regional information. By the same time, they provide regional data, products and feedbacks to Global Production Centres and Lead Centres for respective verification and product optimization of the global-scale information.

The RCC-CM will perform basic functions covering the domain of climate monitoring:

- Monthly monitoring maps: Europe (RA VI; see for example Fig. 1; Hogewind and Bissolli, 2011), Eastern Mediterranean, South Caucasus, Southeast Europe,

- Annual and monthly climate diagnostic bulletins (see for example Fig. 2),

- Monitoring of significant events, 

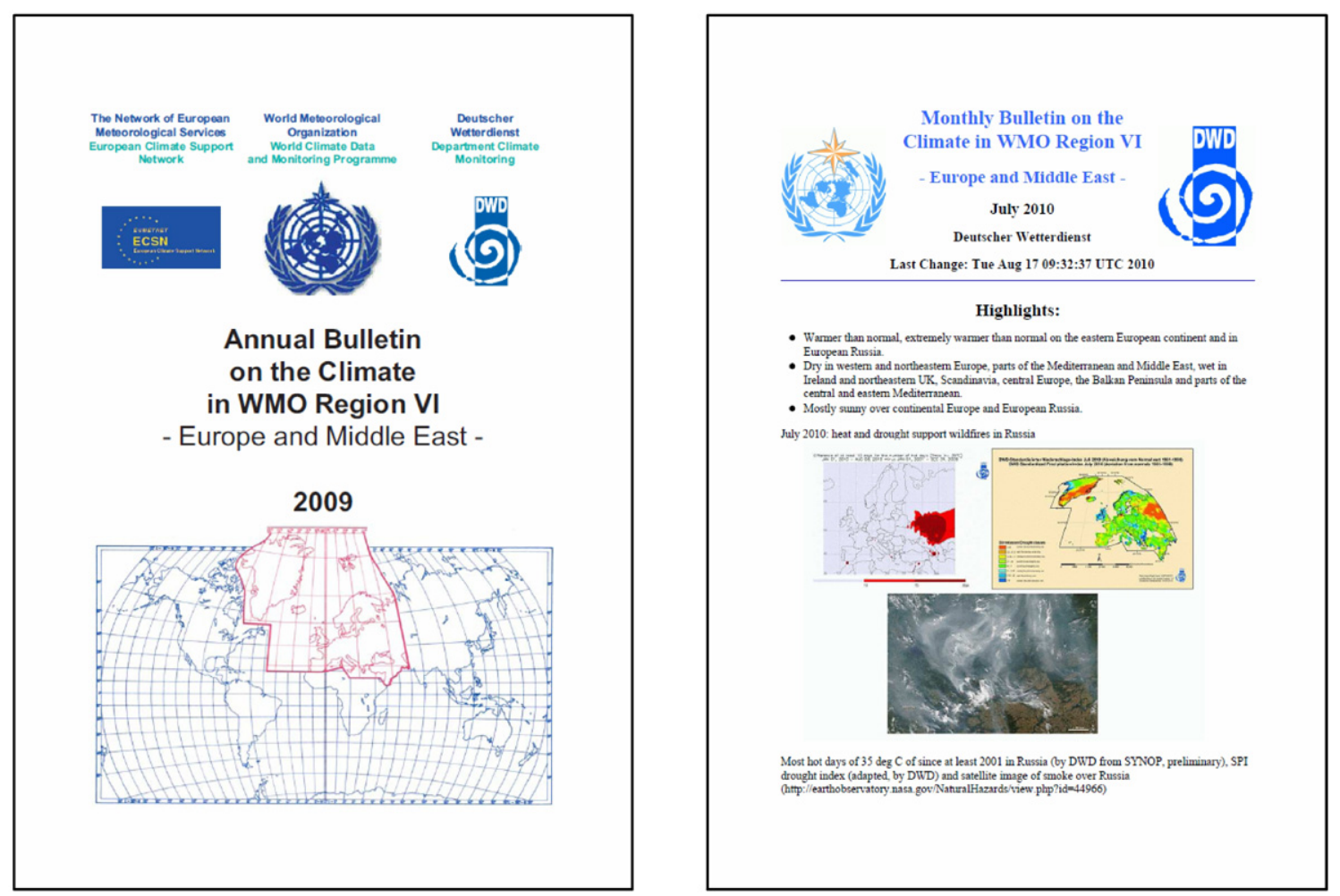

Figure 2. Annual and Monthly Bulletin on the Climate in WMO Region VI.

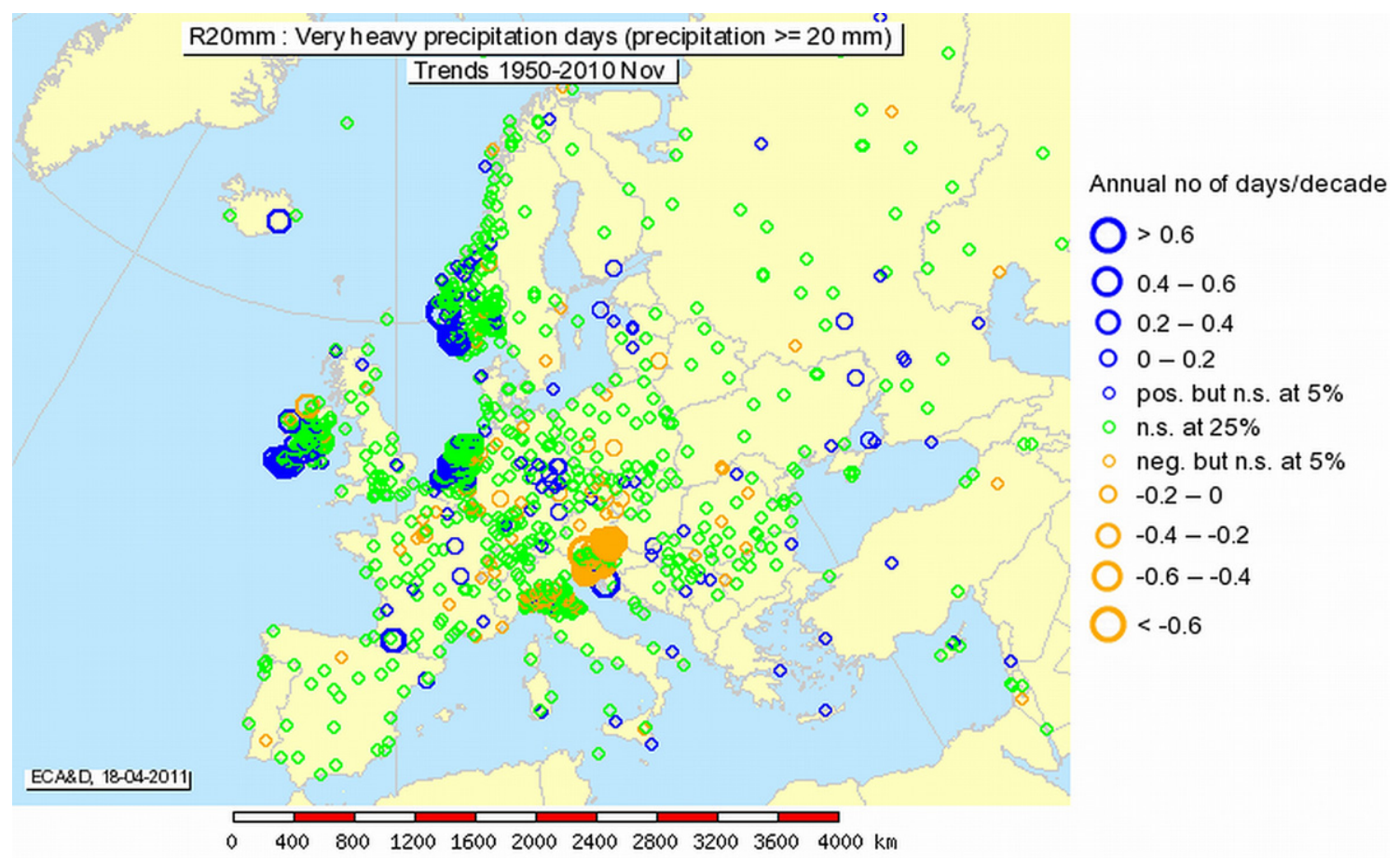

Figure 3. Example map of the trend of very heavy precipitation days ( $\geq 20 \mathrm{~mm})$ in November 1950-2010 (Source: ECA\&D, KNMI). 
Table 1. RCC-CM Product catalogue, Status of 31 December 2010.

\section{RCC-CM Product catalogue}

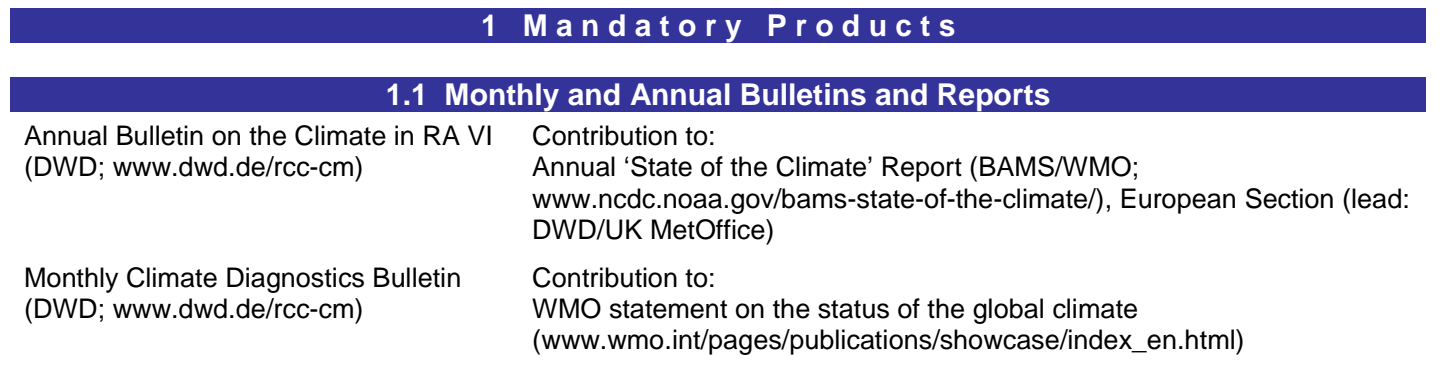

\subsection{Monthly Maps}

Monthly maps of air temperature (DWD; www.dwd.de/rcc-cm)

Monthly maps of snow cover (DWD; www.dwd.de/snowclim)

Monthly maps of cloud coverage (DWD; www.dwd.de/satklim)

Monthly maps of pressure (DWD; www.dwd.de/rcc-cm)

ECA\&D based maps, graphs and trends (temperature, precipitation, extremes indices), based on station data and gridded data (KNMI; eca.knmi.nl)

Monthly anomaly maps of temperature and precipitation for the South Caucasus region (ARMSTATEHYDROMET; www.dwd.de/rcc-cm)
Monthly maps of precipitation

(DWD; www.dwd.de/wzn)

Monthly maps of sunshine duration (DWD; www.dwd.de/rcc-cm)

Monthly maps of water vapour (precipitable water; DWD; www.dwd.de/satklim)

Monthly maps of temperature, precipitation, pressure, wind, humidity (model based) and anomalies with 3 and 12 months overlapping periods (Météo-France; www.meteo.fr/special/CLIM/clim_model.html)

Monthly maps of temperature and precipitation for the Eastern Mediterranean (Turkish State Meteorological Service: emcc.dmi.gov.tr)

Climate anomalies and extremes indices (Republic Hydrometeorological Service of Serbia; SEE/VCCC; www.seevccc.rs)

\subsection{Reference Climatologies}

Temperature (www.dwd.de/rcc-cm)

Snow cover (www.dwd.de/rcc-cm)

Cloud coverage (www.dwd.de/satklim)

ECA\&D based climatologies (temperature, precipitation, extremes indices), based on station data (KNMl; eca.knmi.nl/utils/mapserver/climatology.php)
Precipitation (www.dwd.de/wzn)

Sunshine duration (www.dwd.de/rcc-cm)

Water vapour (www.dwd.de/satklim)

\section{Supplementary Products}

Radiation products:

Surface incoming short-wave radiation

Surface net short-wave radiation

Surface outgoing long-wave radiation

Surface net long-wave radiation

(DWD, www.dwd.de/satklim)

Drought index (modified SPI drought index; DWD, www.dwd.de/rcc-cm)
Cloud coverage indices:

Number of days with cloud cover $<2 / 8$

Number of days with cloud cover $>6 / 8$

Duration of days with cloud cover $<2 / 8$

Duration of days with cloud cover $>6 / 8$

(DWD, www.dwd.de/satklim)

Daily Tmin/Tmax - Temperatur maps

(DWD, in development)

\section{Event Mon I tor Ing}

Significant Weather Event Reports (European scale, www.dwd.de/rcc-cm and http://ecad.knmi.nl/events/selectevents.php)

Significant Weather Event Reports (countries, www.dwd.de/rcc-cm)
Significant Weather Event Calendar

(European scale - monthly events; www.dwd.de/rcc-cm) 
- Reference climatologies and trend maps (see for example Fig. 3, Haylock et al., 2008; van Engelen et al., 2008),

- RA VI climate monitoring WebPortal,

- Climate watches (to be performed in future),

- Training (to be performed in future),

- Research and Development (R\&D)

(to be performed in future).

The pilot RCC-CM generates and distributes various climate monitoring products for the WMO Region VI. Some first products are offered: description of outstanding weather events, maps of various climate quantities and monthly and annual climate reviews ("RA VI Bulletin"). National products for individual countries within the WMO Region VI are provided by the National Meteorological and Hydrological Services of the concerning countries. DWD generates, beside the national products for Germany, also transnational maps and reports for the whole WMO Region VI, based on data and contributions from the countries. A detailed overview of all individual mandatory and supplementary products (e.g. for drought: Pietzsch and Bissolli, 2011) as well as event monitoring information is shown in Table 1.

The climate watch system (CWS; WMO, 2005), which is going to be implemented by RCC-CM in future, will provide advisories and statements for the NHMSs to enable them to inform users, particularly those involved in natural hazards preparedness, mitigation and response, about evolving or foreseen climate anomalies at the regional and national levels, thus allowing them to make informed decisions. The advisories should be based on all available climate information from National Meteorological and Hydrological Services, global producing centres and regional climate centres. The "RA VI Workshop on Climate Monitoring including the Implementation of Climate Watch Systems" (WMO, 2011), held in October 2010 in Offenbach, led to a detailed roadmap for the implementation of a climate watch system.

Updated climate monitoring reports and maps and additional information are available via Internet: www.dwd.de/ $\mathrm{rcc}-\mathrm{cm}$.
Edited by: W. A. Monna

Reviewed by: P. Hechler and another anonymous referee

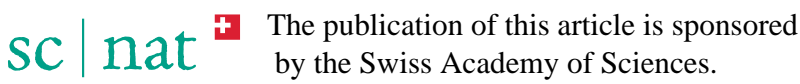

\section{References}

Haylock, M. R., Hofstra, N., Klein Tank, A. M. G., Klok, E. J., Jones, P. D., and New, M.: A European daily highresolution gridded data set of surface temperature and precipitation for 1950-2006, J. Geophys. Res., 113, D20119, doi:10.1029/2008JD010201, 2008.

Hogewind, F. and Bissolli, P.: Operational Maps of Monthly Mean Temperature for WMO-Region VI (Europe and Middle East), Idöjaras, 115, 1/2, 31-49, 2011.

Pietzsch, S. and Bissolli, P.: A modified Drought Index for the WMO RA VI Region, 2011, Adv. Sci. Res., submitted, 2011.

van Engelen, A., Tank, A. K., van der Schrier, G., and Klok, L.: European Climate Assessment \& Dataset (ECA\&D), Report 2008, Towards an operational system for assessing observed changes in climate extremes, KNMI, De Bilt, 68 pp., 2008.

World Meteorological Organization (WMO): Guidelines on Climate Watches, WCDMP-No. 58, 44 pp., 2005.

World Meteorological Organization (WMO) Regional Association VI (Europe): RA VI RCC Implementation Plan, www.wmo.int/pages/prog/dra/eur/documents/RCC\% 20Network/WMO-RAVI-RCC-Implementation-Plan.pdf (last access: 5 June 2011), 2009.

World Meteorological Organization (WMO): Regional Association VI Workshop on Climate Monitoring including the Implementation of Climate Watch Systems, WCDMP-No. 75, WMO/TDNo. 1565, 154 pp., 2011. 